\title{
Active learning in physics a way for rational thinking, a way for development
}

\section{Z. Ben Lakhdar, N. Derbel, Z. Dhaouadi, H. Ghalila, R. Miled, et al.}

Z. Ben Lakhdar, N. Derbel, Z. Dhaouadi, H. Ghalila, R. Miled, S. Lahmar, K. Berrada, R. Channa, A. Outzourhit, "Active learning in physics a way for rational thinking, a way for development," Proc. SPIE 9665, Tenth International Topical Meeting on Education and Training in Optics and Photonics, 966502 (3 June 2007); doi: 10.1117/12.2207802

SPIE Event: Tenth International Topical Meeting on Education and Training in Optics and Photonics, 2007, Ottawa, Ontario, Canada 


\title{
ACTIVE LEARNING IN PHYSICS A WAY FOR RATIONAL THINKING - A WAY FOR DEVELOPMENT
}

\author{
Z. Ben Lakhdar ${ }^{1}$, N.Derbel ${ }^{1}$, Z. Dhaouadi ${ }^{1}$, H.Ghalila ${ }^{1}$, R.Miled ${ }^{1}$, S.Lahmar ${ }^{1}$. \\ K.Berrada $^{2}$, R.Channa ${ }^{2}$ and A.Outzourhit ${ }^{2}$ \\ ${ }^{1}$ LSAMA-STO, Department of Physics, Faculty of Sciences-Tunis-Tunisia. \\ ${ }^{2}$ Faculty of Science Semlalia, Marrakech, Morocco. \\ *zohra.lakhdar@fst.rnu.tn
}

\begin{abstract}
Science Development leads to new concepts, new tools and new techniques. It leads to a society development with new Truth. This Truth is shared by the Society which development is built on Knowledge, on rationality thinking and scientific behavior. This takes its origin in the experimental approach introduced by Ibn Al Haythem in optics at the Xth century.

By the end of the last millennium, this approach-known as Active Learning in Physics- has been adopted in most developed countries in physics education programs. Active Learning in Optics and Photonics- ALOP- is extended actually to some developing countries through a UNESCO program.

A French edition of ALOP takes place through many workshops over Morocco and Tunisia. It aims to build Truth on evidence and not on intuition or personal authority.
\end{abstract}

\section{THE WAY OF SCIENCE FUNCTIONING}

Man looks for Truth. What is Truth?

Truth is defined in Encyclopedia by Diderot and d'Alembert as " a confirmity of our judgments with what are things ".

This means: there is possibility of many truths-upon once judgments- for the same subject!

This jugements is personal, depends on Knowledge, on own initial disposition and life experiences, on human progress.

Then how do we find the "limit" between once believes and Truth which is established? Between once opinion and scientific knowledge?

Human progress: the elimination of ignorance, superstition and prejudice; and the promotion of understanding and awareness is built on education on Science and its methodology.

Development of Scientific knowledge is based on rational thinking based on old knowledge and new experiments, with codes of behaviour.

Scientists in their quest for new knowledge do not know what is relevant. Scientists believe s are "Tentative, not dogmatic; they are based on evidence, not on authority or intuition." B. Russell (1910). That evidence is given by experiment. ".... The test of all knowledge is experiment. Experiment is the sole judge of scientific Truth." (Richard Feynman Nobel price1965)

Tenth International Topical Meeting on Education and Training in Optics and Photonics, edited by Marc Nantel, Proc. of SPIE Vol. 9665, 966502 - (C) 2007 SPIE, OSA, IEEE, ICO doi: $10.1117 / 12.2207802$ 


\section{SOCIETY DEVELOPMENT}

The experimental approach is as "...... a symptom of a wider conceptual revolution that lies at the heart of what has happened to the world along the second millennium" (R. Power-1999); The father of the rise of the experimental method is Abu Ali al-Hassan Ibn al Haythem ( 965 - 1040), who is considered as the Scientist of the second millennium (R.Power 1999).

He solved a scientific debate (Euclide, Ptolemy, ..) that had remained deadlocked for more than 800 years about the mystery of vision and its interpretation that light necessarily travels from the eye to the observed object (M.Serres). He invited observers to stare at the sun and the result was: the eye can be burned. The conclusion was shared by all participants that light starts outside the eye and reflects into it, removing, with a single observation, the very well Systematic theory. Direct observation, controlled looking, experiment, remain the best ways leading to Knowledge. Sharing the experiment, will lead different persons to the exact same understanding.

At the start of this second millennium, Society culture was yet subject of Astrology, Miracles , ... In 1633, Earth is yet the Centre of the World with Sun moving around and Galileo, has been condemned by Church of Rome because he disturbed this beleive and, experimentally, established the Copernicus Heliocentric system!

The scientific method leads, when new evidence comes to light, to accommodation of the theory to that new evidence. Gravity, relativity, and quantum mechanics are concepts which have changed the way we think. This change is shared because it was tested experimentally.

For a scientist, the truth -for the material world- evolutes with the advancement of science "la vérité est fille de son temps ( The truth is daugthter of its Time)" said V. Hugo.

\section{KNOWLEDGE SOCIETY}

At the start of the $3^{\text {rd }}$ millennium, life depends more and more on science, on technology based on physics development (laser systems, computer science, mobile phones, ...). The culture is mainly Science.

Science is present anywhere in our environment! and is at the heart of the functioning and the future of our society :

-a hand-held Global Positioning System satellite receiver can pinpoint its owner's location anywhere on the face of the globe!

-Atom can be seen, its dynamics controlled and new matter is created.

-DNA blueprint of life is decoded; we learn to manage the deployment and expression of genes; ..

-More than 100 exo-planets are discovered;.

-We look for extraterrestrial

-etc.....

This Culture, developed by scientits, is supposed to be universal, without frontiers and with Global dimensions.

\section{STATE OF PHYSICS EDUCATION}

While modern life depends increasingly on science transferred in technology (mobile phones, telematics and informatics, laser systems in medicine and industries, ...c'est déjà dit ci dessus), at the end of the second millennium : 
-The number of students - was decreasing in mathematics, physics and engineering through the developed countries. As an example, fig1- shows the percentage of student evolution in US given by National Science Foundation (NSF).

-The students choose modern branch activities which are close to their environment, connected with life, actual (telecommunication, informatics, microelectronic, biology,.)., and connected with money (fig2).

-The statistics has revealed that Physics suffer in the developed world institutions (A.M.Levy, T. Feder). On figure 3, NSF gives an example of this decrease students enrolment in physics between 1950 and 1990 in US.
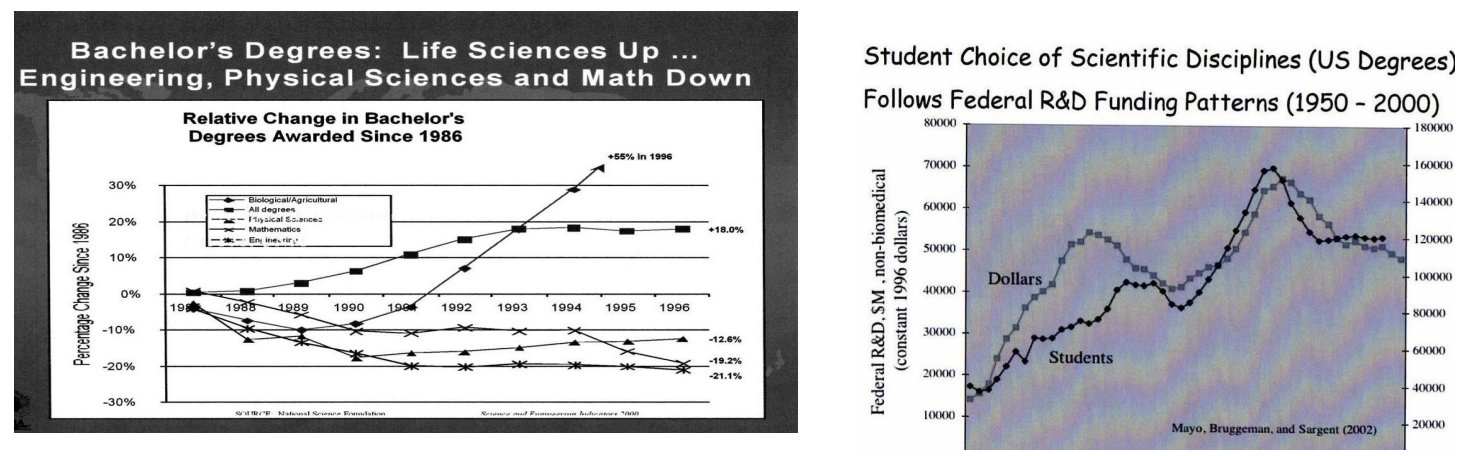

Fig 1: percentage of student evolution in -US in mathematics physics and engineering given by National Science Foundation (NSF).

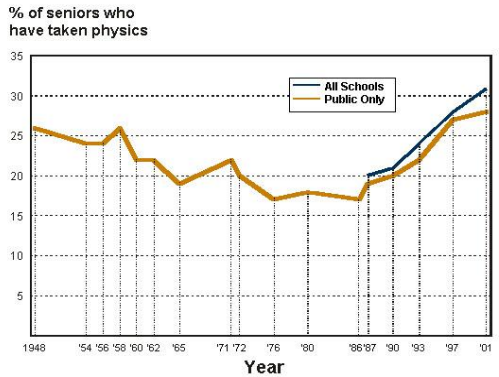

Fig 3: Enrolment School: percentage of senior who have chosen physics (1948-2001)(Statistical Research Center)
Fig 2: Choice of Scientific Disciplines is correlated with Dollars.

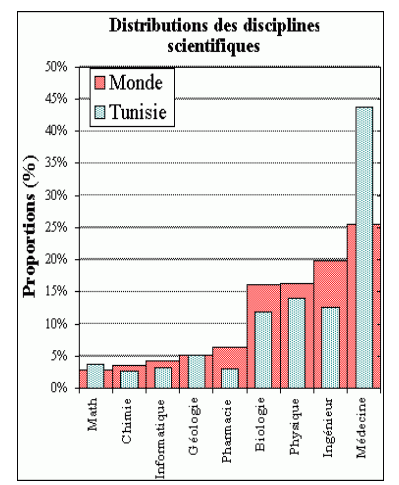

Fig 4:Tunisian scientific research productivity compared to the mean rate productivity of the world

This is dramatic: 'No physics today equals no technology to morrow tomorrow'. The Scientific community (US National Academies of Science, National Research Council, CNRS in France...), tends to resolve this situation in crisis resulting principally from the old educational system which not ou don't follows the new technologic development.. New and innovative attention was paid to education:

- the work life of a physics teacher may be 40 years in which time physics is changing and developing . Continuous professional training and updating are required.

- Physics education and research should be popularised as well as other science disciplines. Physics should be connected to other disciplines with connexion of University to local industries, to schools, to scientific societies, to Society. 
In Developing Nations, science ( mathematics, physics, chemistry ) is relatively learnt at an early age (in Tunisia $\sim 6$ years old for mathematics, $\sim 14$ for physics ) but science and particularly physics is more in crisis than in developed countries. Physics is seen by most people as a tedious experimentation in the laboratory and not a creative and cultural activity, not a source of development.

In Tunisia, almost the total students suffer from physics studies. After "Baccalaureat", a diploma which closes the high school studies, each student can access to University but his studies choice is depending of his results in Baccalaureat and places offered by institutions. Students, in Tunisia, as in developed countries, choose modern branch activities which are close to their environment (medicine, telecommunication, informatics, biology,.)., and connected with money. One of the best choice is also mathematics.

Physics carrier is among the last choice!

On figure 4 , we give the rate of research science productivity of Tunisia compared to the mean rate for research science productivity in the world.( H.Condé). While in mathematics, for which there is no need for experimental activities or in medicine where studies are followed by the best students and connected to the environment ( hospitals), the Tunisian rate productivity is greater than the mean rate in the world, for physics, the world mean rate is larger than the Tunisian one. This is largely due to a severe shortage both of material facilities (schools, laboratories, equipment) and of well qualified physics teachers.

In a world where the progress of Society, the economic and cultural development is increasingly dependent on the science, this situation is no longer acceptable. We should try to bring an understanding of science.

The challenge requires a new methodology of teaching like: "Active learning" (inspired by L.C. Mc Dermott) or "Main à la pâte", inspired by Nobel price G.Charpac.

\section{NEW METHOD FOR EDUCATION: ACTIVE LEARNING IN PHYSICS}

Active learning in Physics-ALP- is an innovative mode of physics teaching, developed over the last decade. It has demonstrated in the US and other developed countries its capacity to enhance student's understanding of basic physics concepts (D.Sokoloff). This approach leads at the beginning of the $3^{\text {rd }}$ millennium to a sensible increase Physics enrolment of student (fig.2, 3).

In this learning strategy, students are guided to construct their knowledge of physics concepts by direct observations of the physical world with Hands on - activity. This scientific method is based on activities in groups following the steps PEDS: predictions, experiments, discussion (qualitative or quantitative description of the observed phenomenon), synthesis. The experimental observations generally lead to questions, questions leads to tentative answers and over all these questions the teacher guides the students to construct their knowledge.

ALP is also, a way for keeping the teaching of physics -which changes continually- up to date 
In 2003 UNESCO under its Physics Programme Division of Basic and Engineering Sciences, launched a Project: "Active Learning in Physics in Developing Countries". This project, made up by $\mathrm{M}$. Alarcon, aims to promote innovations in physics education in developing countries. It is developed for the benefit of universities and senior high school physics teachers. It aims at training teachers to use innovative approach of active learning in teaching physics through a series of workshops.

After one preparing workshop in Manilla -Philippines, the 2 twwo first workshops (20032004) took place in Ghana,. The fisrt one was about mechanics then and the second one was about optics-photonics.

Tunisia (2005), then Morocco(2006) asked UNESCO for ALOP (Active Learning in Optics and photonics) workshops.

Why ALOP?

The project is then focused on optics and photonics because it is an area of experimental physics which is relevant and adaptable to research and educational conditions in many developing countries. We notice an explosion of work in optics. Optics has been termed as "enabling science" because it constitutes the basis of many modern advances in diverse and high technologies (communication, information, transportation, manufacturing, environment control, monitoring, health, medicine) and the new century is entitled the "age of photonics".

The project is developing an activity based on teacher training curriculum on the themes: Introduction to Light and Geometrical Optics; Optics of the Eye; Interference; Diffraction and Spectroscopy; Environmental Optics; Optics in Communication. Modules with activities and appropriate instrumentation are developed under each theme. Inexpensive materials and local fabricated ou made materials have been used. A team of 6 resource persons (from 5 continents) prepared modules, material and lead the workshops.

The workshops are organized via an international working group consisting of representatives from UNESCO, ICTP*, SPIE*, OSA* and ASPEN * and mainly funded by UNESCO with support from ICTP, SPIE and OSA.

\section{IMPACT OF ALOP IN MOROCCO AND TUNISIA}

Participation in the ALOP Workshops was open to different levels of trainers: technicians; high school teachers, researchers and professors at the university- Participants- $~ 40$ - coming from around 10 different countries in each workshop, with big enthusiasm! worked -during the sessions -in groups with not expensive materials and following the steps PEDS( Predict, Experiment, Discuss and Synthetize).

The ALOP workshops provided the trainers with the real difficulties that may encounter our students in physics concept understanding and explained the importance of sharing knowledge. It enhances- for the participants coming from différents regions in Africa ( South Africa, Cameroon, Ethiopia, North Africa, Tanzania ) how Knowledge is personal, and depends on our own initial disposition and life experiences and how sharing experience enhances or leads to the concept understanding. 
Participants appreciated the choice of ALOP modules: the mixture of basic physics modules ( geometric and physics optics) with modules connected to life science ( eyes), environment (atmospheric) and telecommunication.

The connexion of differents disciplines with physics behind is absent in our education system, and the program and the teaching way of physics, in secondary schools as well as in universities, seems far from our environment and boring.ALOP enhances this failure, and participants realize also that each teacher must have some basic understanding of connections of one field with other disciplines.

The active learning workshops led to the conclusion from all participants, technicians or who are also researchers in different fields ( computing science, solid state physics, atomic and molecular physics,..) coming from Faculties or Engineer Schools, that this approach is the process of training people's mind and abilities so that they acquire knowledge and develop skills. They asked to extend that activity to other modules in Physics. They also realised the need of multidisciplinarity and that local fabrication of materials is feasible.

ALOP workshops success led to development of local resource persons for training of trainers, to development of others ALOP workshops over different Universities and secondary schools in Tunisia as well as in Morocco.

New programs, new approach of teaching and policies, high qualified students should be implemented for science physics achievement in our developing countries to lead development of science culture and to lead to a Knowledge Society.

\section{Acknowledgements}

All the authors would like to thank UNESCO for that initiative, UNESCO, ICTP, SPIE and OSA for support of this activity.

\section{REFERENCES}

-Forum recherche en Tunisie-Comité Mixte MCU-H.Condé- 2003

-L.C.M.cDermott,"research on conceptual understanding in mechanics" Physics Today 37,24-32,July 1984

-T. Feder -Physics Today -October 2003

-A.M.Levy. Europhysics news, July/August 2004

-R. Power-New York Times, April 18, 1999-Series on articles on the greatest ideas of the Millennium

-M.Serres. Elements d'histoire des Sciences- Bordas-1989

-D.Sokoloff -Active Learning in Optics and Photonics-Training Manuel- UNESCO-2006

*ICTP: International Centre for Theoretical Physics; *SPIE: International Society for Optical Engineering; *OSA: Optical Society of America; *ASPEN: Asian Physics Education Network. 